Mariana Roberta Lopes Simões

Adelaide De Mattia Rocha

\section{Absenteísmo-doença entre trabalhadores de uma empresa florestal no Estado de Minas Gerais, Brasil}

\author{
Sickness absenteeism among workers of a forestry company in \\ the State of Minas Gerais, Brasil
}

1 Departamento de Enfermagem da Faculdade de Ciências Biológicas e da Saúde da Universidade Federal dos Vales do Jequitinhonha e Mucuri. Diamantina, MG, Brasil.

2 Escola de Enfermagem da Universidade Federal de Minas Gerais. Belo Horizonte, MG, Brasil.

Contato:

Mariana Roberta Lopes Simões

E-mail:

mari_curvelo@yahoo.com.br

Trabalho baseado na dissertação de Mariana Roberta Lopes Simões, intitulada Análise do absenteísmo-doença entre trabalhadores rurais de uma empresa florestal em Minas Gerais, apresentada ao programa de mestrado em Enfermagem da Escola de Enfermagem da Universidade Federal de Minas Gerais, em 2010.

Os autores declaram que este trabalho não foi subvencionado e não apresenta conflitos de interesse.

Recebido: 19/03/2012

Revisado: 16/01/2013

Aprovado: 29/04/2013

\section{Resumo}

Objetivo: conhecer a distribuição do absenteísmo-doença entre os trabalhadores rurais de uma empresa florestal em Minas Gerais. Método: estudo transversal com 883 trabalhadores rurais. Realizou-se o levantamento de todos os atestados médicos emitidos na empresa em um período de um ano (2009). Utilizou-se estatística descritiva (prevalências, médias e desvios padrão). Resultados: a população estudada se caracterizou principalmente por trabalhadores do sexo masculino, jovens e de baixa escolaridade, apresentando uma alta rotatividade no trabalho. Os indicadores de absenteísmo-doença calculados foram índice de freqüência $(3,65)$, de gravidade $(13,67)$ e porcentagem de tempo perdido $(5,7 \%)$. Os agravos mais prevalentes foram os referentes ao aparelho osteomuscular (23,5\%), seguidos do aparelho respiratório (14,3\%), o das lesões, envenenamentos e outras consequências de causas externas $(9,2 \%)$ e os sintomas, sinais e achados anormais de exames (9,0\%). Foi possível observar uma considerável perda de dias por adoecimento entre os trabalhadores, acometendo principalmente o sistema osteomuscular (2203 dias perdidos). Conclusão: o perfil patológico encontrado tem sido apontado como característico das atividades rurais, sobretudo porque requerem grandes esforços físicos do trabalhador e o expõem a condições de trabalho desfavoráveis.

Palavras-chave: saúde do trabalhador; absenteísmo; silvicultura; trabalhador rural.

\begin{abstract}
Objetive: to identify the distribution of sickness absenteeism among workers of a forestry company. Method: a cross-sectional study involving 883 workers from the state of Minas Gerais, Brazil. We collected all medical certificates issued in the company during one year (2009). Basic descriptive statistics was adopted. Results: the population consisted mainly of young male workers with low schooling and a high job turnover. Rates of absenteeism: frequency index 3.65, gravity index 13.67, and absence time percentage $5.7 \%$. The most prevalent causes of sickness absenteeism were linked to complains of the osteomuscular system $(23,5 \%)$ followed by the respiratory system (14,3\%), injuries, poisonings and other external causes consequences (9,2\%) plus symptoms, signs and laboratory abnormal findings (9\%). We could observe a considerable number of sickness absenteeism among rural workers, mainly due to osteomuscular and respiratory system problems (absence of 2203 days). Conclusion: the pathological profile found is in keeping with typical rural activities, that require great physical effort and workers have to cope with adverse working conditions.
\end{abstract}

Keywords: occupational health; absenteeism; forestry; rural worker. 


\section{Introdução}

O século 20 foi caracterizado por um intenso e contínuo processo de mudanças tecnológicas e organizacionais nos cenários produtivos, acarretando grandes transformações nos processos e nas relações de trabalho (SILVA et al., 2005).

Os espaços não urbanizados, principalmente a partir da década de 1980, sofreram inovações, sendo caracterizados por um conjunto de atividades não somente de agricultura, mas também ligadas a várias atividades industriais e de prestação de serviços.

Nesse âmbito, surgiram várias categorias de trabalhadores incorporadas ao novo processo de trabalho no campo. O espaço rural passou a ser marcado pela introdução e diversificação de tecnologias e subordinação ao capital. O impacto dessas mudanças inclui o surgimento de novos perfis de trabalhador, novas habilidades para o trabalho e diversificados agravos à saúde.

Nessa perspectiva, encontra-se o setor florestal brasileiro, em franca expansão, destacando-se na geração de empregos e renda no cenário nacional (SIMOES; ROCHA; SOUZA, 2012).

Segundo dados da Sociedade Brasileira de Silvicultura (2006), no ano de 2005 a produção das reflorestadoras brasileiras representou 3,5\% do Produto Interno Bruto (PIB) nacional, empregando, formalmente, 6,5 milhões de pessoas direta e indiretamente em todos os seus segmentos. Internacionalmente, o Brasil contribuiu com 4,6\% das exportações mundiais de produtos florestais.

Tendo em vista esse crescimento, cabe destacar que a melhoria das condições de saúde dos trabalhadores do campo e a minimização dos impactos ambientais gerados pelos diversos processos produtivos no setor, depende, dentre outros, do reconhecimento e valorização dos condicionantes sociais, culturais e econômicos do processo produtivo agrário (FONTOURA JUNIOR et al., 2011). No meio rural ainda é verificada uma naturalização dos riscos no processo de trabalho tais como os de exposição a agentes químicos, os de picadas de animais peçonhentos, a exposição ao sol, entre outros, que, negligenciados tornam os trabalhadores deste setor ainda mais vulneráveis (FONTOURA JUNIOR et al., 2011).

De modo geral, o crescimento da produção e a modernização da atividade no campo, não representaram mudanças significativas nos modos e nas condições de trabalho desta categoria de trabalhadores (PERES, 2009). Para Pessoa e Rigoto (2012) o desenvolvimento econômico das atividades ligadas ao campo, ainda se baseia em relações de trabalho sem garantias de segurança e conforto e induz a transformações territoriais e no modo de vida dos indivíduos, levando a severos impactos na saúde humana e do meio ambiente.

A exposição dos trabalhadores a condições de trabalho desfavoráveis os leva a um processo conhecido como desgaste, entendido como comprometimento das capacidades corporais e psíquicas do trabalhador (LAURELL; NORIEGA, 1989). O desgaste é contínuo e pode levar o trabalhador a se ausentar dos compromissos de trabalho para cuidar de sua recomposição (SIMOES; ROCHA; SOUZA, 2012).

Como consequência direta da necessidade de cuidados com a saúde ou, geralmente com a falta dela, seja no âmbito físico ou mental, temos o absenteísmo-doença, definido como ausência do trabalhador ao trabalho, que se deve ao adoecimento, podendo ser subdivido em doenças relacionadas ao trabalho, acidentes do trabalho e doenças não relacionadas diretamente ao trabalho (QUICK; LAPERTOSA, 1982; SALA et al., 2009). As ocorrências do absenteísmo-doença, geralmente são conferidas por meio de atestados médicos.

O absenteísmo-doença representa uma situação problemática, tanto para o trabalhador quanto para o empregador, sendo de origem multicausal, geralmente resultante da complexa interação entre questões individuais, laborais e extralaborais. Além de gerar gastos, o absenteísmo desorganiza o ambiente, diminui a produtividade, sobrecarrega os colegas e frustra os trabalhadores (QUICK; LAPERTOSA, 1982).

Embora existam alguns estudos que buscam relacionar agentes etiológicos isolados, acidentes e morbidades específicas do trabalho, são escassos os estudos sobre a importância do trabalho na determinação do adoecimento comum (FASSA; FACCHINI; DALL'AGNOL, 1996). Normalmente esse adoecimento é constituído por agravos de etiologia múltipla e representa perdas na capacidade para o trabalho com consequentes ausências ao trabalho.

As pesquisas sobre o adoecimento no trabalho através do absenteísmo-doença têm revelado altas prevalências e forte relação com o trabalho (SIMOES; ROCHA; SOUZA, 2012). O estabelecimento dessa relação é complexa, principalmente quando se trata de trabalhadores rurais, sobre os quais pouco conhecimento é produzido.

Desta forma, esta pesquisa busca analisar a distribuição do absenteísmo-doença entre os trabalhadores rurais de uma empresa florestal em Minas Gerais, conforme perfil sociodemográfico e ocupacional, como passo fundamental para o planejamento de ações de melhorias na qualidade de vida destes trabalhadores. 


\section{Metodologia}

Esta pesquisa foi aprovada pelo Comitê de Ética e Pesquisa da Universidade Federal de Minas Gerais sob parecer $\mathrm{n}^{\circ} 378 / 08$.

Trata-se de um estudo epidemiológico, descritivo, de corte transversal, desenvolvido em uma empresa florestal de reflorestamento de Eucalipto, na zona rural da região central de Minas Gerais, durante o ano de 2009, abordando o absenteísmo-doença entre os trabalhadores. O absenteísmo-doença foi definido como ausência do trabalhador ao trabalho devido ao adoecimento, entretanto, por questões operacionais e didáticas, nesta pesquisa os acidentes de trabalho bem como as faltas sem atestado médico não foram incluídas.

A população pesquisada foi composta por todos os trabalhadores da empresa, em atividade por algum período daquele ano, inclusive os que foram desligados ou admitidos no decorrer do período. Foram excluídos aqueles que se mantiveram afastados do trabalho durante todo o período do estudo.

As variáveis estudadas foram as:

- Variáveis sociodemográficas - como escolaridade, sexo e idade, em faixas etárias, quais sejam: 18 a 28 anos, 29 a 38,39 a 48,49 a 58 e mais de 58 anos.

- Variáveis ocupacionais - tempo na empresa, como sendo o tempo de vínculo, decorrido a partir da admissão até o momento do atestado médico ou até o final do estudo para aqueles que não tiveram atestados no período - esse tempo foi categorizado conforme a característica da distribuição em menor que 1 ano, de 1 a 2 anos, de 3 a 5 anos e maior que 5 anos de vínculo; e função, considerada aquela exercida pelo trabalhador no ano do estudo.

- Variáveis do absenteísmo-doença - ocorrência do atestado; número de dias de afastamento; causa referida conforme Classificação Internacional de Doenças - 10 a revisão (CID-10) (ORGANIZAÇÃO MUNDIAL DA SAÚDE, 1997).

Foram excluídos do estudo os atestados emitidos no período por motivo de acidente de trabalho. Optou-se por não incluí-los no estudo por entender que este evento requer uma abordagem diferenciada e específica. Foram excluídos também atestados médicos emitidos com data anterior ao início do estudo, as licenças por parto e para acompanhamento de pessoa da família, que não se configuram como causas de tratamento da saúde do próprio trabalhador, apesar de originadas a partir de um atestado médico.

Para organização dos dados foi utilizada uma planilha da ferramenta Microsoft Office Excel, preenchida e atualizada pela própria pesquisadora. Estas informações foram transferidas para o programa estatístico Statistical Package for Social Science (SPSS) versão 16.0. Foi feita a caracterização da população conforme variáveis pesquisadas, que consistiu no cálculo das médias, medianas e desvios padrão. Para o cálculo da prevalência de atestados médicos na população, foi considerado apenas a ocorrência ou não do evento, independente se o trabalhador apresentou 1 ou mais atestados no período. Este cálculo foi realizado apenas para evidenciar o peso do evento na população e dentre suas categorias, já que, a medida de prevalência não constitui uma medida de risco e sim o número de pessoas afetadas na população em um período específico.

Posteriormente, os atestados médicos foram distribuídos conforme a CID-10, duração do evento, tempo de trabalho na empresa e função; separados ainda de acordo com a idade e sexo.

Foram calculados índices de frequência, índice de gravidade, porcentagem de tempo perdido conforme Couto, 1987, seguindo as fórmulas:

Esses indicadores são reconhecidos internacionalmente nos estudos de absenteísmo e permitem estabelecer comparações.
Índice de frequência:

Índice de gravidade:

Porcentagem de tempo perdido: número de atestados no período

efetivo médio do período

número de dias perdidos no período

efetivo médio do período

número de dias perdidos no período x 100

número programado de dias de trabalho no período 


\section{Resultados}

\section{Perfil do universo da pesquisa}

O grupo de estudo foi composto pelo total de trabalhadores da empresa em 2009, equivalente à 883 trabalhadores, sendo a média mensal de 560 trabalhadores ao mês, todos residentes na área urbana do município onde se encontra a empresa.

Em relação ao sexo, a grande maioria (93\%) dos trabalhadores era do sexo masculino. Quanto à idade, $49 \%$ foram menores de 38 anos, com a média de 33 anos, 10,54 anos de desvio-padrão (DP), mediana de 30 anos e apenas $2 \%$ tiveram idade igual ou superior a 58 anos. Destaca-se a baixa escolaridade, embora apenas $1 \%$ de analfabeto, quase $74 \%$ estudaram de 1 a no máximo 8 anos, ou seja, o primeiro grau.

Considerando o "tempo de empresa" como sendo o período entre a admissão e o final do estudo, para aqueles que permaneceram até o final, ou até o último dia trabalhado, para aqueles que se desligaram da empresa durante o estudo, a média de tempo na empresa foi de 29,6 meses (DP $=40,4)$ e mediana de 15 meses, com extremos que variaram de 3 meses a 27 anos de tempo de empresa. Constatou-se que grande parcela da população (44\%) é relativamente nova na empresa, com menos de 1 ano de vínculo.

\section{Descrição dos atestados médicos - Absenteísmo-doença}

Dos 883 trabalhadores que compuseram a população do estudo, um total de 409 não teve nenhum atestado médico no período, os demais, tiveram no mínimo uma ocorrência, sendo que 15 trabalhadores apresentaram 15 ou mais atestados no ano. A distribuição dessa ocorrência está apresentada na Tabela 1.

Mais de $70 \%$ dos atestados foram com perda de tempo igual a 1 dia, entretanto, $46,6 \%$ do total de dias perdidos foram por atestados de 15 dias ou mais conforme demonstrado na Tabela 2.

Os indicadores de absenteísmo-doença na população foram: índice de frequência igual a 3,65 afastamentos iniciados por trabalhador no ano, de gravidade igual a 13,67 dias perdidos por trabalhador no ano e a porcentagem de tempo perdido igual a 5,7\%.

Com relação à causa referida, ou diagnóstico referido no atestado médico, obteve-se a distribuição, categorizada conforme Capítulos da CID-10, apresentada na Tabela 3.

Tabela 1 Ocorrência de atestados médicos entre trabalhadores de uma empresa florestal. Minas Gerais, 2009

\begin{tabular}{|c|c|c|}
\hline $\begin{array}{c}N^{\circ} \text { de eventos (atestados) } \\
\text { apresentados no ano }\end{array}$ & $N^{o}$ de trabalhadores & $\begin{array}{c}\text { Porcentagem }(\%) \text { de } \\
\text { trabalhadores }\end{array}$ \\
\hline 0 & 409 & 46,3 \\
\hline 1 & 127 & 14,4 \\
\hline 2 & 82 & 9,3 \\
\hline 3 & 60 & 6,8 \\
\hline 4 & 47 & 5,3 \\
\hline 5 & 33 & 3,7 \\
\hline 6 & 24 & 2,7 \\
\hline 7 & 18 & 2,0 \\
\hline 8 & 21 & 2,4 \\
\hline 9 & 14 & 1,6 \\
\hline 10 & 13 & 1,5 \\
\hline 11 & 7 & 0,8 \\
\hline 12 & 5 & 0,6 \\
\hline 13 & 4 & 0,5 \\
\hline 14 & 4 & 0,5 \\
\hline 15 a 25 & 15 & 1,7 \\
\hline Total & 883 & 100,0 \\
\hline
\end{tabular}


Tabela 2 Atestados médicos entre os trabalhadores florestais de uma empresa, segundo número de dias de afastamento por atestado e número total de dias perdidos. Minas Gerais, 2009

\begin{tabular}{lcccc}
\hline $\begin{array}{c}\text { Tipo de atestado segundo o tempo de } \\
\text { afastamento }\end{array}$ & \multicolumn{2}{c}{ Eventos } & \multicolumn{2}{c}{ Dias perdidos } \\
& Quantidade & Porcentagem & $* n$ & Porcentagem \\
\hline Atestados de 1 dia & 1459 & 71,3 & 1459 & 19,1 \\
Atestados de 2 dias & 211 & 10,3 & 422 & 5,5 \\
Atestados de 3 dias & 108 & 5,3 & 324 & 4,2 \\
Atestados de 4 a 10 dias & 167 & 8,2 & 1047 & 13,7 \\
Atestados de 11 a 15 dias & 57 & 2,8 & 832 & 10,9 \\
Atestados superiores a 15 dias & 45 & 2,2 & 3571 & 46,6 \\
\hline Total & 2047 & 100,0 & 7655 & 100,0 \\
\hline
\end{tabular}

*n: número de dias perdidos calculado pela somatória dos dias de afastamento de cada atestado

Tabela 3 Número de atestados médicos, número de dias perdidos e média de dias perdidos por atestado, segundo Capítulo da CID-10*, entre os trabalhadores florestais de uma empresa. Minas Gerais, 2009

\begin{tabular}{|c|c|c|c|c|c|c|c|c|c|c|c|c|c|c|c|c|c|c|c|}
\hline & $\begin{array}{c}\text { Cap } \\
1\end{array}$ & $\begin{array}{c}\text { Cap } \\
\text { II }\end{array}$ & $\begin{array}{l}\text { Cap } \\
\text { IV }\end{array}$ & Cap & $\begin{array}{c}\text { Cap } \\
\text { VI }\end{array}$ & $\begin{array}{l}\text { Cap } \\
\text { VII }\end{array}$ & $\begin{array}{l}\text { Cap } \\
\text { VIII }\end{array}$ & $\begin{array}{l}\text { Cap } \\
\text { IX }\end{array}$ & $\begin{array}{c}\text { Cap } \\
X\end{array}$ & $\begin{array}{c}\text { Cap } \\
X I\end{array}$ & $\begin{array}{l}\text { Cap } \\
\text { XII }\end{array}$ & $\begin{array}{l}\text { Cap } \\
\text { XIII }\end{array}$ & $\begin{array}{l}\text { Cap } \\
\text { VIV }\end{array}$ & $\begin{array}{l}\text { Cap } \\
X V\end{array}$ & $\begin{array}{l}\text { Cap } \\
\text { XVIII }\end{array}$ & $\begin{array}{l}\text { Cap } \\
\text { XIX }\end{array}$ & $\begin{array}{l}\text { Cap } \\
X X\end{array}$ & $\begin{array}{l}\text { Cap } \\
X X I\end{array}$ & $\underset{\ln f}{S}$ \\
\hline $\begin{array}{l}N^{\circ} \text { de } \\
\text { licenças }\end{array}$ & 72 & 3 & 2 & 19 & 24 & 26 & 50 & 28 & 292 & 92 & 48 & 481 & 97 & 3 & 184 & 188 & 5 & 142 & 291 \\
\hline $\begin{array}{l}N^{\circ} \text { de dias } \\
\text { perdidos }\end{array}$ & 220 & 62 & 2 & 120 & 299 & 113 & 119 & 138 & 470 & 331 & 314 & 2203 & 215 & 13 & 217 & 2005 & 22 & 258 & 534 \\
\hline $\begin{array}{l}\text { Média de } \\
\text { dias por } \\
\text { licença }\end{array}$ & 3,1 & 20,7 & 1,0 & 6,3 & 12,5 & 4,3 & 2,4 & 4,9 & 1,6 & 3,6 & 6,5 & 4,6 & 2,2 & 4,3 & 1,2 & 10,7 & 4,4 & 1,8 & 1,8 \\
\hline
\end{tabular}

* Organização Mundial da Saúde (1997)

Nota: Cap. I - Doenças infecciosas e parasitárias; Cap. II - Neoplasias; Cap. IV - Doenças endócrinas, nutricionais e metabólicas; Cap. V - Transtornos mentais e comportamentais; Cap. VI - Doenças do sistema nervoso; Cap. VII - Doenças do olho e anexos; Cap. VIII - Doenças do ouvido; Cap. IX - Doenças do aparelho circulatório; Cap. X - Doenças do aparelho respiratório; Cap. XI - Doenças do aparelho digestivo; Cap. XII - Doenças de pele e tecido subcutâneo; Cap. XIII - Doenças osteomusculares; Cap. XIV - Doenças do aparelho geniturinário; Cap. XV - Gravidez, parto e puerpério; Cap. XVIII - Sintomas, sinais e achados anormais de exames; Cap. XIX - Lesões, envenenamentos e outras consequências de causas externas; Cap. XX - Causas externas de morbidade e mortalidade; Cap. XXI - Causas administrativas.

Obs: A não representação dos capítulos III, XVI e XVII se deve ao fato da não identificação de eventos com referência aos mesmos.

Nota-se que os capítulos X (doenças do aparelho respiratório), XIII (do aparelho osteomuscular), XIX (as lesões, envenenamentos e outras consequências de causas externas), e o XVIII (sintomas, sinais e achados anormais de exames) foram os que mais se destacaram em números de ocorrência de atestados, com 1145 eventos, ou seja, 54,8\% do total, e ao mesmo tempo de perda de dias, juntos responsáveis pela perda de 4895 dias, 63,82\% do total. Entretanto, faz-se importante destacar o cap. XIII, doenças do aparelho osteomuscular, recordista em atestados e em dias perdidos, sozinho, contabilizou a emissão de 481 atestados (23,5\% do total) com 2203 dias perdidos no período. Neste grupo, destacaram-se as dorsopatias
(62\%), destas, 60,7\% foram dorsalgias (CID-M54). Em seguida temos os transtornos de tecidos moles não especificados (CID-M79) representando 20\% das ocorrências de agravos do sistema osteomuscular.

Entre as doenças do aparelho respiratório (14,3\% do total de atestados) destacaram-se as infecções agudas das vias aéreas superiores, CIDs J00 a J06, com $65 \%$, seguidas pelas gripes, $30 \%$.

As lesões, envenenamentos e outras consequências de causas externas (cap. XIX) contribuíram com 9,2\% dos atestados; destacaram-se os CID S60 à S69, referentes a traumatismos do punho e da mão, seguido pelos S90 à S99, traumatismos do tornozelo e do pé. 
No cap. XVIII, sintomas, sinais e achados anormais de exames, com 9,0\% dos atestados, destacaram-se o CID- R51, cefaléia, com 85 ocorrências (46,2\%), o CID-R68, outros sintomas e sinais gerais, com o total de 17 ocorrências $(9,2 \%)$, o CID-R10, dor abdominal e pélvica com 15 ocorrências (8,15\%) e o CID-R25.2, câimbras e espasmos com 12 ocorrências (6,5\%).

Com relação à perda média de dias por atestado, entre as categorias de maior ocorrência, Cap. X, XIII, XVIII e XIX, destacou-se a perda média de dias do Cap. XIX, média de 10,7 dias perdidos por atestado, o que caracteriza maior gravidade ou maior tempo médio de recuperação.

A não representação de alguns capítulos da CID10 na Tabela 3, quais sejam os capítulos III, XVI, XVII, se deve ao fato da não existência de eventos com referência aos mesmos.

\section{Discussão}

\section{Perfil da população}

O reconhecimento do perfil dos trabalhadores da empresa é muito importante para o desenvolvimento e planejamento de treinamentos, orientações e interferências positivas no ambiente de trabalho (SILVA; SOUZA; MINETTI, 2002). Especificamente, o levantamento do perfil dos trabalhadores potencializa o entendimento de eventos como a ocorrência de atestados médicos, de que trata a presente pesquisa.

Esse perfil é condizente com a necessidade do trabalho em atividades mais pesadas, que exigem trabalhadores com maior força física e higidez (PIGNATI; MACHADO, 2005; MACIEL et al., 2011).

A escolaridade é um dos fatores determinantes de grande relevância para o auto cuidado com a saúde. Andrietta (2004) comenta que este é um dos poucos setores da economia que ainda absorvem formalmente mão-de-obra analfabeta. Entretanto, Maciel et al. (2011) destaca que a mecanização e o aumento no uso da tecnologia no campo tende a transformar o perfil do trabalhador, exigindo um pouco mais de instrução, embora a baixa escolaridade ainda seja realidade entre os trabalhadores deste setor no país.

Ainda dentro da descrição do perfil, temos o tempo na empresa, $44 \%$ da população estudada tinha menos de um ano de trabalho. Essa variável apresentou uma expressiva diferença entre a média e mediana, fato que revela a dispersão da distribuição, com extremos que variaram de 3 meses a 27 anos de vínculo contínuo com a empresa. Essa constatação revela a alta rotatividade dos trabalhadores.
Estudos confirmam que cerca de $40 \%$ dos trabalhadores rurais possuem menos de 12 meses de vínculo nas empresas (ANDRIETTA, 2004; SILVA et al., 2009). Esse evento ainda tem suas razões pouco conhecidas, entretanto, podem contribuir para tal: as condições adversas de trabalho presentes atualmente no meio rural, a extrema exigência física, além da sazonalidade histórica da atividade. Todas essas hipóteses merecem maiores esclarecimentos.

\section{Ocorrência de atestados médicos}

Na população de estudo, o perfil do adoecimento foi vislumbrado através dos atestados médicos. Mais da metade dos trabalhadores (54\%) apresentaram pelo menos um atestado médico no ano. Apesar de elevados, esses dados podem ser comparados a outras categorias, como, por exemplo, a de enfermagem, sobre a qual existem vários estudos neste sentido, com prevalências que costumam ser ainda maiores (REIS et al., 2003; SANCINETTI et al., 2009). Entretanto, no meio rural estes números representam uma realidade que necessita ser explorada com relação aos seus determinantes.

Cabe destacar que a compreensão do absenteísmo-doença é complexa, envolve inúmeros fatores além de simplesmente o adoecimento. Apesar de todas as melhoras na oferta e qualidade da assistência à saúde, as taxas do absenteísmo-doença têm aumentado de forma considerável nos países industrializados (DANATRO, 1997). Estudos coincidem em sinalizar que o absenteísmo-doença constitui-se em um complexo fenômeno de interação entre os fatores individuais, que residem no fator humano, tomando o trabalhador como unidade básica da organização do trabalho, suas expectativas, necessidades, valores, habilidades, conhecimento e outros; os fatores laborais, relacionado às condições do ambiente de trabalho e dos processos realizados; e os extralaborais, principalmente representados pelos fatores sociais e culturais (BARBOZA; SOLER, 2003; COUTO, 1987; DANATRO, 1997; SILVA; MARZIALE, 2006). Em se tratando de trabalhadores rurais, alguns fatores são identificados como determinantes no processo de adoecimento, são eles: o esforço físico e acelerado ritmo de trabalho; o calor intenso, poeira, fuligem e presença de animais peçonhentos; e as condições de vida e a pobreza desses indivíduos (ROCHA; MARZIALE; ROBAZZI, 2007; ROMANKOW, 2007).

No total, foram emitidos no período do estudo 2.047 atestados contabilizando 7.655 dias perdidos com afastamentos, o que equivale a dizer que aproximadamente 22 trabalhadores não compareceram à empresa durante todo o ano estudado. Esse número mostra, grosseiramente, a perda que representa o absenteísmo-doença também para a organização. 
Mais de 70\% dos atestados foram com perda de apenas um dia, destes, $55 \%$ foram oriundos de atendimentos de urgência. Considerando que esse tempo não é suficiente para cura, e por estar em grande número, esta situação representa um ponto crítico a ser tratado.

Uma explicação para a existência de grande número de atestados de curta duração poderia ser, conjugada a outros fatores, a exposição excessiva ao sol e sobrecarga física como fatores do trabalho causadores de exaustão ao final da jornada e que potencialmente desencadeiam agravos de curta duração e desgaste nos trabalhadores florestais em questão. Essa dinâmica, reconhecida como resultado da interação das cargas de trabalho e o homem, geralmente é peculiar aos modos de produção (LAURELL; NORIEGA, 1989).

Pode-se inferir que grande parte dos atestados de curta duração não se refere a doenças instaladas, mas figura como uma possibilidade de recomposição da força de trabalho.

A discussão dos índices do absenteísmo-doença entre trabalhadores rurais florestais se torna difícil, uma vez que, não existem estudos com essa abordagem. Entretanto, podemos fazer algumas considerações baseados em Couto (1987), que relata que, para a realidade brasileira, podemos classificar como índices de absenteísmo-doença excessivos valores com índice de frequência (If) maiores que 0,10 por mês. Isto é, num determinado mês, para cada 100 trabalhadores ocorreram mais de 10 afastamentos por doença. $\mathrm{O}$ autor considera a porcentagem de tempo perdido acumulado maior que 1,2\% alto, recomendando que a situação do trabalho deve ser avaliada. Na presente pesquisa encontramos índice de frequência em 3,65 ao ano, referente a uma média de 0.3 ao mês e porcentagem de $5,7 \%$ de tempo perdido ao ano, taxas bem acima do apontado, o que constata a relevância do problema para o setor florestal.

\section{Ocorrência dos principais agravos}

Os agravos relacionados nos atestados médicos foram distribuídos conforme os Capítulos e Subcapítulos da CID-10 (ORGANIZAÇÃO MUNDIAL DA SAÚDE, 1997). Foi evidenciado que os Cap. X, XIII, XVIII e XIX, respectivamente referentes às doenças do aparelho respiratório, do aparelho osteomuscular, aos sintomas, sinais e achados anormais de exames e as lesões, envenenamentos e outras consequências de causas externas, foram os que mais se destacaram em números de ocorrência de atestados e, ao mesmo tempo, de perda de dias.

As doenças do Capítulo XIII, aparelho osteomuscular, foram destaque na população. Um estudo desenvolvido no Iran evidenciou a sobrecarga do sistema osteomuscular em atividades rurais através relatos de queixas osteomusculares em $66 \%$ dos moradores da comunidade rural pesquisada (DAVATCHI et al., 2009). Embora em países diferentes, com utilização de metodologias e índices diferentes, é possível estabelecer a relação desses dados com a presente pesquisa, na medida em que há evidenciação de problemas osteomusculares entre indivíduos que desempenham atividades rurais, o que vem reforçar o carater hostil de tal atividade ao sistema osteomuscular humano.

Dentre os danos ao sistema osteomuscular, os distúrbios dolorosos da coluna vertebral, genericamente denominados lombalgias e dorsalgias, constituem uma importante causa de transtorno de saúde, absenteísmo relacionado ao trabalho e de invalidez permanente (ORGANIZACIÓN INTERNACIONAL DEL TRABAJO, 1989). Esses agravos foram também evidenciados nesta pesquisa como destaque entre os agravos do sistema osteomuscular.

Para além das questões ocupacionais, um estudo realizado na Grécia (ANTONOPOULOU et al., 2009) apontou a existência de forte associação entre a ocorrência de distúrbios osteomusculares em comunidades rurais e a baixa qualidade de vida e saúde mental nesta comunidade. Esse achado levanta outras hipóteses que poderiam contribuir para as elevadas prevalências deste evento na população estudada, já que as condições de doença mental, por dificuldades diagnósticas, nem sempre são identificadas com precisão. Ao encontro deste raciocínio, temos a definição da multicausalidade dos agravos à saúde dos trabalhadores e da interação potencializadora entre as cargas de trabalho, reforçando o entendimento do adoecimento para além da doença (LAURELL; NORIEGA, 1989).

Em segundo lugar se destacaram as doenças do aparelho respiratório, responsáveis por 470 dias perdidos. A poluição do ar nos ambientes de trabalho associa-se a uma gama de doenças do trato respiratório que acometem desde o nariz até o espaço pleural. Os agravos respiratórios podem ser potencializados nos ambientes de trabalho rural, entre outros motivos, pela baixa ingestão de água, pelo clima e umidade da região e pela presença de poeira (SIMÕES; ROCHA; SOUZA, 2012).

Em seguida tem-se o Cap XIX, lesões, envenenamentos e outras consequências de causas externas, aparece com significativa representatividade em número de atestados, $9 \%$ do total, e, principalmente, em número de dias perdidos, $26 \%$ do total de dias perdidos com atestados no ano.

Levando-se em consideração que neste estudo os acidentes de trabalho não foram envolvidos, esse resultado causa uma estranheza. No entanto, numa análise detalhada da ocorrência desses agravos na população estudada, foi evidenciado que estavam 
relacionados principalmente a traumas, sendo alguns deles em decorrência de acidentes de trânsito, motocicleta principalmente, não caracterizados como de trajeto, e sim, reflexos da violência urbana, além das práticas esportivas como o futebol, também não relacionadas ao trabalho. É importante destacar que a população estudada, embora composta por trabalhadores rurais, reside em periferias urbanas.

Os traumas também foram a terceira maior causa de atestados no estudo de Quick e Lapertosa (1982), sendo atribuídos, já naquele ano, à violência urbana. Esses autores apresentaram inclusive causas de óbitos da população no ano do estudo corroborando a afirmativa.

Completando o conjunto dos capítulos da CID10 mais prevalentes, temos o XVIII, sintomas, sinais e achados anormais de exames, responsáveis por 184 afastamentos e 217 dias (média de 1,13 dias por atestado). Dentre as causas levantadas nesta categoria destacaram a cefaleia, dores abdominais e a câimbra ou espasmo, que podem estar relacionados diretamente ao desgaste físico relativo a exposição ao sol, à produtos químicos, à desidratação e a má alimentação risco evidenciados nestes ambientes de trabalho (SILVA et. al., 2005; PERES, 2009; MACIEL et. al., 2011; SIMÕES; ROCHA, 2012). Essa constatação vem reforçar a ocorrência de atestados de curta duração (70\% dos encontrados neste estudo) como reflexo de um desgaste imediato, e que pode representar a necessidade de recomposição do trabalhador diante de suas condições de trabalho.

Com relação às limitações deste estudo, por se tratar de uma pesquisa documental, dois viéses são possíveis: os dias não trabalhados por motivo de tratamento da saúde, em que os trabalhadores podem ter faltado ao trabalho, mas não apresentaram atestados médicos para justificar essa ausência, bem como a apresentação de atestados com diagnóstico que não condizem com a realidade.

\section{Conclusão}

Pôde-se identificar que na população estudada houve uma maioria de trabalhadores do sexo masculino, jovens e de baixa escolaridade e uma alta rotatividade no trabalho, características já contempladas e comprovadas por outros estudos que abordavam o trabalhador do meio rural. Nesta população foi possível visualizar também a grande perda de dias de trabalho justificadas por atestados médicos.

Entre os agravos referidos, destacaram-se o acometimento do aparelho osteomuscular, do respiratório, as lesões consequentes de causas externas e os sintomas, sinais e achados anormais de exames. Esse perfil patológico tem sido apontado como característico das atividades rurais, principalmente porque requerem grandes esforços físicos do trabalhador e os expõem a condições de trabalho desfavoráveis, estabelecendo uma relação que pode prejudicar o trabalhador.

Destacou-se também a grande ocorrência de atestados de curta duração sugerindo a necessidade de recomposição do trabalhador diante das cargas de seu trabalho. Este aspecto representa ainda uma situação importante a ser esclarecida.

Considerando o grande volume de participantes e de atestados, e o período estudado, é possível concluir que os resultados apresentados evidenciam a realidade vivenciada pelos trabalhadores florestais aqui estudados e despertam para a necessidade de se investigar os fatores determinantes no processo de adoecimento que podem estar contribuindo para o absenteísmo-doença nessa categoria de trabalhadores.

Além disso, os resultados desta pesquisa podem representar uma base para elaboração de programas pontuais e estratégicos na busca pela melhoria das condições de saúde e trabalho na atividade rural, de forma especial no trabalho florestal.

\section{Contribuições de autoria}

As duas autoras participaram igualmente, desde o planejamento do projeto, coleta e análise dos dados até a escrita e a aprovação final do manuscrito.

\section{Referências}

ANDRIETTA, A. J. Evolução do perfil dos trabalhadores da agropecuária paulista de 1985 à 2002. Informações Econômicas, São Paulo, v. 34, n. 9, p. 7-19, set. 2004 .

ANTONOPOULOU, M. D. et al. Studying the association between musculoskeletal disorders, quality of life and mental health. A primary care pilot study in rural Crete. Greece. BioMed Central Musculoskeletal Disorders, Grécia, v. 10, n. 143, p. 1-8, Nov. 2009.

BARBOZA, D. B.; SOLER, Z. A. S. G. Afastamentos do trabalho na enfermagem: ocorrência com trabalhadores de um hospital de ensino. Revista 
Latino-Americana de Enfermagem, Ribeirão Preto, v. 11, n. 2, p. 177-183, mar./abr. 2003.

COUTO, H. A. Temas de saúde ocupacional: coletânea dos cadernos Ergo. Belo Horizonte: Ergo, 1987.

DANATRO, D. Ausentismo laboral de causa médica en uma instituición pública. Montevideo: 1994-1995. Revista Médica del Uruguay, Montevideo, v. 13, n. 2, p. 101-109, ago. 1997.

DAVATCHI, F. et al. The prevalence of musculoskeletal complains in a rural area in Iran: a WHO-ILAR COPCORD study (stage 1, rural study) in Iran. Clinical Rheumatology, Iran, v. 28, n. 11, p. 1267-1274, Nov. 2009.

FASSA, A. G.; FACCHINI, L. A.; DALL'AGNOL, M. M. Trabalho e morbidade comum em indústria de celulose e papel: um perfil segundo o setor. Cadernos de Saúde Pública, Rio de Janeiro, v. 12, n. 3, p. 297-307, jul./set. 1996.

FONTOURA JUNIOR, E. E. et al. Relações de saúde e trabalho em assentamento rural do MST na região de fronteira Brasil-Paraguai. Trabalho Educação e Saúde, Rio de Janeiro, v. 9, n. 3, p. 379-397, nov. 2011.

LAURELL, A. C.; NORIEGA, M. Processo de produção e saúde: trabalho e desgaste operário. São Paulo: Hucitec, 1989.

MACIEL, M. R. A. et al. Caracterização sócioeconômica do trabalhador temporário da indústria canavieira em Lagoa da Prata, Minas Gerais, Brasil. Revista Sociedade \& Natureza (On-line), Uberlândia, v. 23, n. 2, ago. 2011.

ORGANIZACIÓN INTERNACIONAL DEL TRABAJO/ OIT. Absentismo, causas y control. In: Enciclopédia de Salud e Seguridad en el trabajo. Madrid: Ministerio de Trabajo y Asuntos Sociales; Subdirección General de Publicaciones, v. 1, p. 5-12. 1989.

ORGANIZAÇÃO MUNDIAL DA SAÚDE. Classificação Estatística Internacional de Doenças e Problemas Relacionados à Saúde - $1^{\mathrm{a}}$ Revisão. CID-10. São Paulo: Edusp, 1997.

PERES, F. Saúde, trabalho e ambiente no meio rural brasileiro. Ciência \& Saúde Coletiva, Rio de Janeiro, v. 14, n. 6, p. 1995-2004, 2009.

PESSOA, V. M.; RIGOTTO, R. M. Agronegócio: geração de desigualdades sociais, impactos no modo de vida e novas necessidades de saúde nos trabalhadores rurais. Revista Brasileira de Saúde Ocupacional, São Paulo, v. 37, n. 125, p. 65-77, 2012.

PIGNATI, W. A.; MACHADO, J. M. H. Riscos e agravos à saúde e a vida dos trabalhadores das indústrias madeireiras de Mato Grosso. Ciência \& Saúde Coletiva, Rio de Janeiro, v. 10, n. 4, p. 961-973, out./dez. 2005.
QUICK, T. C., LAPERTOSA, J. B. Análise do absenteísmo em usina siderúrgica. Revista Brasileira de Saúde Ocupacional, São Paulo, v. 10, n. 40, p. 62-67, 1982.

REIS, R. J. et al. Fatores relacionados ao absenteísmo por doença em profissionais de enfermagem. Revista de Saúde Pública, São Paulo, v. 37, n. 5, p. 616-623, out. 2003.

ROCHA, F. L. R.; MARZIALE, M. H. P.; ROBAZZI, M. L. C. C. Poverty as a predisposing factor of illness tendencies in sugar cane workers. Revista LatinoAmericana de Enfermagem, Ribeirão Preto, v. 15, n. esp., p. 736-741, set./out. 2007.

ROMANKOW, J. Medical certification in workers involved in logging and wood-processing. Archiwum Medycyny Sadoweji Kryminologii, Polônia, v. 57, n. 1, p. 89-94, Jan./Mar. 2007.

SALA, A. et al. Licenças médicas entre trabalhadores da Secretaria de Estado da Saúde de São Paulo no ano de 2004. Cadernos de Saúde Pública, Rio de Janeiro, v. 25, n. 10, p. 2168-2178, out. 2009.

SANCINETTI, T. R. et al. Absenteísmo - doença na equipe de enfermagem: relação com a taxa de ocupação. Revista da Escola de Enfermagem - USP, São Paulo, v. 43, n. esp. 2, p. 1277-1283, dez. 2009.

SILVA, E. P. et al. Caracterização da saúde dos trabalhadores florestais envolvidos na extração de madeira em regiões montanhosas. Revista Árvore, Viçosa, v. 33, n. 6, p. 1196-1174, dez. 2009.

SILVA, J. M. et al. Agrotóxico e trabalho: uma combinação perigosa para a saúde do trabalhador rural. Ciência \& Saúde Coletiva, Rio de Janeiro, v. 10, n. 4, p. 891-903, out./dez. 2005.

SILVA, D. M. P. P.; MARZIALE, M. H. P. Condições de trabalho versus absenteísmo-doença no trabalho de enfermagem. Ciência, Cuidado e Saúde, Maringá, v. 5, p. 166-172, dez. 2006. Suplemento.

SILVA, K. R.; SOUZA, A. P.; MINETTI, L. J. Avaliação do perfil de trabalhadores e das condições de trabalho em marcenarias no município de Viçosa-MG. Revista Árvore, Viçosa, v. 26, n. 6, p. 769-775, nov./dez. 2002.

SIMÕES, M. R. L.; ROCHA, A. M.; SOUZA, C. Fatores associados ao absenteísmo-doença dos trabalhadores rurais de uma empresa florestal. Revista Latino-Americana de Enfermagem, Ribeirão Preto, v. 20, n. 4, p. 718-726, 2012.

SOCIEDADE BRASILEIRA DE SILVICULTURA. Fatos e números no Brasil Florestal. São Paulo: SBS, nov. 2006. Disponível em: <http://www.ipef.br/estatisticas/ relatorios/SBS-2005.pdf>. Acesso em: 15 jul. 2009. 